\title{
CALIPSO NÃO SE CONSOLAVA COM A PARTIDA DE ULISSES: A ILHA DA IGUALDADE*
}

\author{
STÉPHANE DOUAILleR
}

\begin{abstract}
RESUMO: Quando, em 1987, Jacques Rancière publicou $O$ mestre ignorante, de Joseph Jacotot, o método universal de emancipação intelectual e o aprendizado de leitura sem mestre explicador inscreviam o nome de seu autor no livro de ouro dos precursores da escola e da pedagogia. Após uma releitura do estatuto que, em 1911, o Dictionnaire de pédagogie de Ferdinand Buisson lhe havia conferido, Stéphane Douailler, professor do departamento de filosofia da Universidade Paris VIII, busca ressaltar, neste breve artigo, algumas das linhas de ruptura graças às quais o livro de Jacques Rancière conseguiu estilizar a aventura de Jacotot num paradigma excepcional da questão filosófica da igualdade das inteligências e da emancipação universal, na contramão das verdades em torno das quais, historicamente, a escola se fundou.
\end{abstract}

Palavras-chave: Joseph Jacotot. Axiomática. Naturalismo pedagógico. Bernard Perez. Inteligibilidade igualitária.

\section{Calypso Could not Get over the Departure of Ulysses: AN ISLE OF EQUALITY}

ABSTRACT: When, in 1987, Jacques Rancière published The ignorant schoolmaster, by Joseph Jacotot, the universal method of intellectual emancipation and reading training without an explaining master definitively entered the gallery of school and education precursors. After reviewing the status he was given by the Dictionnaire de Pédagogie edited by Buisson, in 1911, Stéphane Douailler, professor at the department of philosophy at the University of Paris 8, attempts to draw out some of the rupture lines through which Rancière's book succeeded to stylize the adventure of Jacotot into

\footnotetext{
* Tradução de Alain François, com revisão técnica de Lílian do Valle.

** Departamento de Filosofia da Universidade de Paris VIII, Vincennes/Saint-Denis. E-mail: s.douailler@free.fr
} 
an exceptional paradigm of the philosophical question of intelligence equality and universal emancipation, that went against the tide of the truths around which school was historically founded.

Key words: Joseph Jacotot. Axiomatics. Pedagogic naturalism. Bernard Perez. Egualitarian inteligibility

e há uma frase que fica ecoando nos ouvidos de quem acaba de ler l'Enseignement universel, langue maternelle, publicado por Joseph Jacotot em Louvain, em 1822, é bem esta: "Calipso não se consolava com a partida de Ulisses". Ler esse manual - que, a exemplo de muitos outros, surgiu num momento de plena expansão da demanda escolar do século XIX, oferecendo por meio dos exercícios de seu método os préstimos de um novo sistema de ensino - ou, melhor dizendo, relê-lo - pois, ao que parece, até mesmo quem jamais o leu só poderia dele retirar um conhecimento segundo, instalado nessa posição pelos diversos motivos que, na verdade, fazem do método Jacotot uma questão inatual, pedagogicamente ultrapassada, ausente do horizonte efetivo dos reformadores que trabalham no aperfeiçoamento da escola e que, portanto, no melhor dos casos, dele fazem uma questão histórica, senão filosófica - reler, dizia eu, esse manual, por qualquer desses motivos históricos ou filosóficos, implica de fato reviver a experiência, facultada a cada um, de que toda a pedagogia poderia caber nessa frase: "Calipso não se consolava com a partida de Ulisses".

Mas, para tanto, seria preciso reaprender o caminho ao longo do qual algum simples fatos se transfiguram em luminosas evidências, o primeiro deles sendo de que a pergunta: "Com que Calipso não conseguia se consolar?" clama pela resposta "Com a partida de Ulisses"; e, em seguida, de que a apreensão intelectual dessa necessidade que liga a resposta à pergunta é adquirida ao se "soletrar", pacientemente, "Calipso", "Calipso não", "Calipso não conseguia" etc.; e, ainda, de que tal apreensão nos fornece, também, o modelo de todas as apreensóes que, a essa, nosso espírito ainda puder relacionar.

Com efeito, reler o manual, experimentando mais uma vez, em todo seu poder, a frase "Calipso não se consolava com a partida de Ulisses" - vislumbrando aí, em virtualidade, o todo da pedagogia, significa fazer-se sensível à igualdade intelectual entre essa frase e qualquer outra produção da inteligência recebida desde o ponto em que ela se soletra; significa, igualmente, situar-se nesse ponto desde o qual o livro que, sob o título de $O$ mestre ignorante, Jacques Rancière 
dedica a Joseph Jacotot, leva a inteligência à sua incandescência, sob o axioma da igualdade.

Examinemos, para avaliar alguns de seus desafios, o segundo e o terceiro exercícios que, segundo o método, se fariam possíveis a partir da soletração repetida da frase: "Calipso não se consolava com a partida de Ulisses".

Segundo exercício: - O que é uma deusa? - É um ser imortal servido por ninfas. - Será que todas as deusas eram servidas por ninfas? - Não sei. Então, por que disse isto? - Para responder. - Era preciso dizer: Calipso era servida por ninfas, mas não sei se todas as deusas eram servidas por ninfas.

Terceiro exercício: - Qual o estado de uma pessoa aflita? - Ela busca a solidão. - É verdade que Calipso estava triste e buscava a solidão; mas quem disse que todas as pessoas que sofrem buscam a solidão? - Todo mundo sabe disto.

A extemporaneidade do método Jacotot, que tais exercícios pareceriam ilustrar, poderia ser assim enunciada: poucos alunos ainda lêem as Aventuras de Telêmaco, de Fénelon. Eles já não aprendem a ler nesse livro, ou em qualquer outro do gênero. "Claudine vai à escola" substituiu "Calipso não se consolava com a partida de Ulisses" - o que, aliás, os reformadores costumam encarar como um progresso decisivo; e um de seus argumentos consiste em destacar o valor do terceiro exercício, em detrimento do segundo. Pois, sem dúvida, o segundo exercício pareceria acumular tudo o que torna a tarefa da aprendizagem mais difícil: a referência a seres imaginários, como deusas e ninfas, completamente exteriores à experiência e às representações infantis; uma codificação mitológica desses seres que não só é culturalmente especializada, mas também datada; um acesso desigual e potencialmente marcado pelo conflito social ao universo de cultura que serve de fábula e de matéria prima para o exercício.

Em contrapartida, pela subsunção da singularidade de Calipso à humanidade comum, tanto quanto pela cotidianidade de seu tema, o terceiro exercício forneceria ao trabalho de discernimento que está no princípio da leitura o suporte de um sentido verdadeiramente comum - perfeitamente vislumbrado e exprimido por Jacotot, quando conclui o diálogo pedagógico com um "todo mundo sabe disto". Pela feição imprimida ao terceiro exercício - proveniente, ao que parece, de um ponto onde a prática pedagógica teria aprendido a coincidir com o repertório de experiências dos alunos, ao invés de sobrecarregar 
sua imaginação com uma mixórdia herdada de uma tradição discutível - eis que o método Jacotot já anunciaria, ele próprio, essa modernidade escolar que concluiu de forma cada vez mais determinada serem boas as razões de se substituir "Calipso não se consolava com a partida de Ulisses" por "Claudine vai à escola". E isso seria tão mais pacífico que nada, entre os princípios do método, justificava um apego particular à fábula de Calipso, ou ao livro de Fénelon: afinal, não fora senão o acaso que colocara sob os olhos de Jacotot, quando de sua descoberta, uma tradução holandesa do Telêmaco de Fénelon, e não outro texto; qualquer livro teria igualmente servido e apenas o simples hábito, em si mesmo injustificável, o teria levado a continuar propondo, como elemento primeiro de instrução, a soletração de "Calipso", "Calipso não" etc. ao invés de qualquer outra frase.

Enfim, por essa ou qualquer outra via, poder-se-ia arrastar o método Jacotot até a modernidade, arrancando-o de suas contingências primeiras para lhe conferir, em meio aos tantos progressos efetuados desde então pela pedagogia, seu lugar de direito, que caberia à sua descoberta, assim como às diversas possibilidades que, tal como outros métodos inovadores, ele teria pressentido e que ainda poderiam, eventualmente, fazer prova de certa fecundidade.

Ao menos é nesse sentido que, já no final daquele século, o Dictionnaire de pédagogie, de Ferdinand Buisson, entende o método. $\mathrm{O}$ artigo a ele dedicado realiza uma dupla avaliação. Animado por uma ardente filantropia que conduzia à atenção especial aos pobres, e por um verdadeiro entusiasmo pela educação, Jacotot teria vislumbrado e afirmado toda uma série de "verdades essenciais": a igualdade das inteligências, pela qual se deveria depreender que: "todos os homens têm as mesmas faculdades e os mesmos meios para aprender, todos podem e devem ter acesso aos benefícios da instrução"; o princípio segundo o qual tudo está em tudo, que enunciaria que o espírito humano sempre chega ao conhecimento pela combinação de um mesmo fundo de idéias e operaçóes primordiais; o imperativo a ele associado, de saber uma coisa e a ela relacionar todo o resto, que demandaria a construção de um núcleo de conhecimentos primeiros, formado por um rico fundo de fatos, palavras e idéias, de modo a se poder "aprender, comparar, distinguir, verificar, isto é, aproximar as coisas desconhecidas das conhecidas"; e finalmente, a conseqüência: cada um pode instruir-se sozinho, sem mestre explicador, que traduziria o fato de que "cabe ao aluno fazer todo o trabalho" enquanto "o mestre observa, interroga, controla, estimula, muito mais do que dirige". 
À luz dessa releitura, Jacotot despontaria como alguém que soube encontrar e enunciar verdades que até hoje acompanham a expansão, no mundo inteiro, da forma escolar. Além de muitas outras curiosidades guardadas nos museus pedagógicos, seu sistema teria produzido uma formulação bastante singular para um pequeno número de idéias gerais, chamadas a se constituírem o patrimônio hoje comum de convicção pedagógica. Mas, apenas enunciada, essa primeira avaliação conduz a uma outra. Para identificar, em seu método, as verdades comuns e essenciais da pedagogia, seria ainda necessário depurar suas formulaçôes dos defeitos corriqueiros do "inovador" - ou seja, de suas extravagâncias e provocaçōes. Para o autor do artigo do Dictionnaire de pédagogie, Bernard Perez, seriam três, essencialmente, os defeitos de Jacotot: (1) "um pouco absoluto demais no que se refere aos princípios, um pouco irregular demais e, mesmo, freqüentemente bizarro em sua exposição", ao concentrar teorias e abusar de deduçóes sistemáticas, ele teria deixado que "verdades essenciais se transformassem, sob sua pena, em paradoxos"; (2) na "sublime esperança e nobre empreitada de levar o pobre e o ignorante à emancipação universal", ele teria sobredeterminado, em suas relações com os adversários de seu método, o conflito "que reflete suas opiniōes políticas e revolucionárias"; (3) finalmente, "absolutamente confiante em seu sistema", ele não se haveria empenhado o bastante em explicá-lo, o que the teria valido incompreensão e zombarias diversas. A estrutura dessa crítica, que atribui a Jacotot um erro reiterado nos planos da formalização teórica, dos interesses políticos e da propaganda pedagógica, certamente mereceria muitos comentários.

Mas é igualmente possível acompanhar o tratamento proposto pelo redator do artigo - que não fora, a rigor, encarregado de uma discussão de fundo com Jacotot, ou sobre os desdobramentos práticos que sua obra suscitou, na época, na Inglaterra, na Rússia ou no Sul da Alemanha, mas de inscrevê-la, do modo mais ordenado e útil ao progresso que fosse possível, nessa grande síntese em que o Dictionnaire de pédagogie de Ferdinand Buisson pretendia se constituir para o mundo escolar. Neste horizonte, o principal defeito de Jacotot, ou, pelo menos, aquele a requerer maior atenção era o excesso lógico, pelo qual as verdades da pedagogia eram transformadas em paradoxos. Talvez sugere Bernard Perez - isso fosse a marca de sua especialização em matemática.

Porém, mais profundamente, e até mesmo nessa reflexão anódina que põe em jogo os traços psicológicos do espírito, o que faz Bernard Perez é, de fato, submeter o sistema de Jacotot à operação 
instituinte da pedagogia, que presidiu ao desenvolvimento da forma escolar: a instituição de um afastamento pelo qual a produção lógica das verdades é submetida à autoridade da natureza. Referindo-se ao próprio pivô do método Jacotot - o axioma da igualdade das inteligências Bernard Pérez escreve: "Fatos que o matemático Jacotot não levou em consideração (...) jamais teriam escapado ao olhar do pedagogo naturalista - que ele não soube ser"; o autor conclui, então, ser necessário submeter o axioma de Jacotot à "séria revisão" desse naturalismo. E é, sem dúvida, desde o ponto de vista de uma natureza - de alguma naturalização do lógico, do logos - que se poderiam enunciar as críticas dirigidas às verdades lógicas, por seu caráter absoluto, sua irregularidade, sua extravagância, seu conteúdo paradoxal, tanto quanto estabelecer o programa de purificação desses excessos. Ora, é justamente esse programa de naturalização do logos que a pedagogia e, a seguir, as ciências da educação têm se esforçado para implementar, paralelamente ao desenvolvimento histórico da forma escolar.

O profundo êxito de $O$ mestre ignorante, de Jacques Rancière, é o de propor uma releitura da aventura de Jacotot que permanece inteiramente exterior a essa operação de naturalização própria à pedagogia escolar. Daquele que Bernard Pérez denomina o Jacotot matemático, Rancière retém, fundamentalmente, alguém que soube situar a relação pedagógica e emancipadora de que se fez arauto sob a determinação estrita de um axioma, que afirma a igualdade das inteligências. E o livro de Rancière restitui precisamente toda a força dessa fundaçáo axiomática, que poderíamos tentar exprimir pelo enunciado que o método jacotista decerto parece autorizar: conhecer a igualdade das inteligências, e a isso relacionar todo o resto. Essa é, efetivamente, a função de um axioma: permitir que a ele tudo possa ser relacionado, que tudo o que, a partir dele, se faz sirva para verificá-lo, para desenvolvê-lo, para desdobrá-lo em suas conseqüências. Afirmar um enunciado cuja verdade não se situe em outro lugar, além do sistema que a ele se vincula com força e coerência; sustentar o enunciado - cuja possibilidade a matemática, justamente, pode atestar - de uma única relação com o sistema de que é protocolo de abertura. E, portanto, dar-se um ponto de partida rigorosamente independente de outras fontes de verdades, como os "fatos" invocados por Bernard Pérez - sejam eles os fatos que coloca "a montante" da obra educativa, fatos "atuais", suscetíveis de estudos positivos, a manifestar a desigualdade das inteligências, desmentindo e obrigando a rever tanto o sistema quanto o voluntarismo de Jacotot, ou sejam os fatos, igualitários, que a 
educação não pode deixar de colocar como horizonte último dos progressos que dela se esperam e como ideal para seus mestres, sem negar o projeto da modernidade, sob a forma de igualdade política, de superação das barreiras entre os espíritos, de supressão dos orgulhos de castas, de corporaçōes, de sexos, da emergência da "aptidão universal de todos para toda instrução e para todo tipo de obra intelectual ou manual".

Axiomática, a igualdade das inteligências acionada pelo método jacotista não pertence nem ao reino desigualitário de uma natureza presente, nem ao reino igualitário de uma natureza por vir. E ela, efetivamente, recusa a visão desses fatos que se impõem ao olhar do "pedagogo naturalista" como encenação do grande trabalho que a cultura desdobra entre os dois reinos - impedindo que ele perceba que, na verdade, esse grande trabalho cultural da educcação também não pára de naturalizar, de embrutecer e de convencer de sua ignorância aquele que pretende educar. $\mathrm{O}$ axioma da igualdade das inteligências se distancia desses fatos e volta a seu sistema: "Calipso", "Calipso não" etc.

A origem matemática que o artigo do Dictionnaire de pédagogie de Ferdinand Buisson atribui à axiomática jacotista não deve, assim, ser mal-interpretada. A pedagogia emergente do século XIX possivelmente institui um novo equilíbrio entre as ciências lógicas e as ciências naturais. Para ela, reconhecer em Jacotot um espírito matemático nada mais era do que uma maneira de reconhecê-lo refratário a esse novo equilíbrio, assimilando-o ao antigo equilíbrio em que, no século XVIII, ainda dominava a preeminência da matemática. No entanto, nada é decerto mais alheio à aventura singular de Jacotot, do que o conflito orquestrado pela pedagogia, desde seu nascimento, entre as ciências lógicas e naturais, para determinar que campos disciplinares imprimiriam com suas marcas as naturalizaçôes em que sua ação se basearia. Matemático, Jacotot certamente não o é nos termos desse conflito, mas talvez muito mais no sentido do sistema espinosista e de sua formulação more geometrico. Matemático, ele o é, de certa forma, em sentido filosófico - no sentido dos ecos que a axiomática espinosista e a relação absoluta com a realidade da natura naturans souberam despertar, à mesma época; e de maneira, no fundo, bastante semelhante, em vários grandes filósofos. Pois é realmente uma estranha "matemática", uma matemática um tanto inesperada, aquela cujo sistema reconduz, de modo infinito, a soletrar "Calipso", "Calipso não"... O desafio, portanto, como Rancière o demonstra admiravelmente em $O$ mestre ignorante, não é a lógica - mas o logos. $\mathrm{O}$ desafio não deixa de ser o de uma natureza - mas da natureza 
do ser falante. O desafio da diferença entre um ser natural e a natureza do ser falante - que seria ainda talvez convincente interpretar como natura naturans, ou como identidade da natura naturans e da natura naturata e, logo, em última instância, como sistema.

Ao se afastar da grande saga educativa dos fatos que se atêm a fazer coincidir a divisão entre natureza e cultura com a tensão entre o reino das desigualdades presentes e o das igualdades por vir, ao reconduzir, de modo infinito, à soletração do sistema, Jacotot concede, em matéria educativa, a primazia à doação imediata e completa de inteligibilidade, conferida pela instalação no sistema, e não à lenta e progressiva acumulação dos saberes. Ainda que aprender possivelmente sempre conduza a conjugar os dois, a instituir simbolicamente $o$ real na figura inaugural de um todo significante, a refazer pacientemente o percurso que unifica todos os nós da rede instituída, importa, antes de qualquer outra coisa, estabelecer a primeira como fundamento, se a escolha é visar menos a descoberta embrutecedora - à qual falta ainda e sempre um nó no saber adquirido - do que a promessa emancipadora, que parte a cada vez da transformação inaugural das coisas em um sistema inteligível de signos adequado à diversidade das ocorrências de um sujeito falante. Nessa instituição inaugural, o mestre pode, sem dúvida, muito além do que simplesmente deixar "o aluno fazer todo o trabalho" enquanto ele "observa, controla e estimula, muito mais do que dirige" - como resume Bernard Pérez, e como repete a vulgata pedagógica. O mestre pode garantir ao aluno a potência de inteligibilidade igualitária que se origina da instituição particular de ser falante em que a ação pedagógica o projetou. Ele pode garantir ao aluno essa potência, ao outorgá-la em plenitude imediata, a ser simplesmente efetivada, verificada, mantida sob a tensão de uma incansável atenção.

Com isso, Jacotot decerto modifica totalmente a função do mestre. Não apenas no conhecido espectro que inscreve as posiçôes docentes entre os dois extremos do autoritarismo e do laisser-faire jogo de que a pedagogia não parece se cansar e do qual, efetivamente, jamais poderá se liberar, enquanto inscrever sua ação na dupla hélice de um trabalho operado pela cultura sobre a natureza e de uma naturalização das verdades lógicas; esse mesmo jogo ao qual se mantêm aprisionadas todas as descendências do socratismo, cujas operações de deslocamento e inversão dos lugares - por mais imaginativas que sejam - concernem todavia à lenta e progressiva acumulação dos saberes. Muito mais do que isso, a modificação situa 
a função do mestre na posição de fiador da potência de inteligibilidade que é liberada de forma imediata e igualitária, por força de um sistema que a desapega dos saberes dos quais imagina proceder. Pois essa é, justamente - logo após a opinião da desigualdade das inteligências e o sentimento de agir sobre seres naturais - a terceira superstição comum à pedagogia: a de ter origem nos saberes. Nada há, certamente, de mais propagado do que a crença de que os saberes unificam o conjunto da iniciativa pedagógica, marcando seu início e seu fim, legitimando as transmissões dos mestres, motivando as aquisições dos alunos, justificando os esforços que a sociedade consente em fazer pela educação. O saber faria o mestre; o desejo de saber, o aluno. Assim, em toda evidência, se formulariam as definiçóes primeiras e o contrato primordial e último.

Contudo, como bem se pode perceber, é essa evidência que Jacques Rancière faz em pedaços, já pelo próprio título, em $O$ mestre ignorante. Sem pretender reduzir todo o programa dos deslocamentos enunciados por esse título à diferença aqui mencionada entre o sistema de inteligibilidade conferido ao ser falante, em sua condição de falante, e o universo dos saberes, poder-se-ia, segundo sugestão do próprio livro, referi-lo à imagem da ilha. A imagem poria em destaque um outro tema - fartamente desenvolvido pela obra de Rancière, que obriga a distinguir, na relação de ensino, a função social exercida nos espaços socialmente instituídos (nos quais as operações da partilha, circulação e transmissão dos saberes reproduzem mais ou menos fielmente a própria reprodução da sociedade, em sua consistência maciçamente desigualitária) e a relação emancipadora, que, unindo duas inteligências sob o axioma de igualdade, submete o lugar do seu encontro a uma verdadeira metamorfose: no caso, um livro que ensina que existem deusas servidas por ninfas, numa ilha de igualdade.

Em "Causes et raisons des îles désertes", Gilles Deleuze relembra que o movimento trazido por um homem a uma ilha não rompe o deserto, mas intensifica sua perfeição, autorizando a enunciação do paradoxo: "que seres existem numa ilha deserta?". A essa pergunta, prossegue, a única resposta seria que já nelas existe o homem, em verdade idêntico à própria ilha deserta e, portanto, como "homem pouco comum, absolutamente separado e absolutamente criador".

Recebido e aprovado em fevereiro de 2003. 
Referências bibliográficas

DELEUZE, G. Causes et raisons des îles désertes. In: . L'île déserte et autres textes. Paris: Minuit, 2002.

JACOTOT, J. Enseignement universel. Langue maternelle. Louvain: 1822.

PEREZ, B. Jacotot in Ferdinand Buisson. Nouveau dictionnaire de pédagogie et d'instruction primaire. Paris: Hachette, 1911.

RANCIÈRE, J. Le maître ignorant (cinq leçons sur l'émancipation intellectuelle). Paris: Fayard, 1987. 